\title{
Relation of arsenic exposure to lung cancer among tin miners in Yunnan Province, China
}

\author{
P R TAYLOR, ${ }^{1}$ Y-L QIAO, ${ }^{2}$ A SCHATZKIN, ${ }^{1}$ S-X YAO,${ }^{3}$ J LUBIN, ${ }^{4}$ B-L MAO, ${ }^{3}$ \\ J-Y RAO,${ }^{2}$ M McADAMS, ${ }^{5}$ X-Z XUAN,${ }^{3}$ J-Y LI ${ }^{2}$
}

From the Cancer Prevention Studies Branch, 'Division of Cancer Prevention and Control, National Cancer Institute, Bethesda, MD, USA, Department of Epidemiology, ${ }^{2}$ Cancer Institute, Chinese Academy of Medical Sciences, Beijing, Labor Protection Institute, ${ }^{3}$ Yunnan Tin Corporation, Gejiu, People's Republic of China, Biostatistics Branch, ${ }^{4}$ Division of Cancer Etiology, National Cancer Institute, Bethesda, MD, and Information Management Services, Inc, Silver Spring, MD, USA

\begin{abstract}
The relation of mining and smelting exposure to arsenic and lung cancer was studied among tin miners in Yunnan Province in the People's Republic of China. Interviews were conducted in 1985 with 107 living tin miners who had lung cancer and an equal number of age matched controls from among tin miners without lung cancer to obtain information on risk factors for lung cancer including detailed history of employment and tobacco use. Occupational history was combined with industrial hygiene data to estimate cumulative arsenic exposure. Similar methods were also used to estimate radon exposure for simultaneous evaluation in this analysis. The results indicate that subjects in the highest quarter of cumulative arsenic exposure have a relative risk of 22.6 compared with subjects without exposure after adjusting for tobacco and radon exposure, and a positive dose response relation was observed. Simultaneous evaluation of arsenic and tobacco exposure indicates a greater risk for arsenic, whereas simultaneous assessment of arsenic and radon exposure suggests radon to be the greater risk. There is no evidence of synergism between arsenic and tobacco exposure. Among arsenic exposed individuals, cases of lung cancer have longer duration but lower average intensity of arsenic exposure than controls, indicating that duration of exposure to arsenic may be more important than intensity in the aetiology of lung cancer. Finally, risk of lung cancer among workers exposed to arsenic only in mining is only slightly less than for miners whose exposure to arsenic was limited to smelting, although risks are highest when workers were exposed to both mining and smelting.
\end{abstract}

Based largely on the results of studies among workers manufacturing arsenical pesticides or working in copper smelters, inorganic arsenic is considered to be a lung carcinogen in man. ${ }^{1}$ Few studies, however, have had sufficient data to evaluate a dose response relation, to distinguish effects of tobacco from arsenic exposure, or to evaluate specifically the risk of lung cancer due to arsenic from underground mining exposure.

In 1985 we conducted a case-control study among employees of the Yunnan Tin Corporation (YTC) where lung cancer has for decades been the main cause of death. ${ }^{2}$ We report here the results of our investigation of arsenic among both mining and smelting workers of the YTC.

Accepted 13 February 1989

\section{Subjects and methods}

\section{STUDY SUBJECTS}

All male cases of lung cancer between the ages of 35 and 80 who were reported to the Labor Protection Institute of the YTC during 1971-84 who were alive in 1985 and resided in the Gejiu area were included in this study. A pool of controls was chosen systematically by selecting every 20th person from a master list of all living past or present workers from the YTC who lived in the Gejiu area. The master list was organised hierarchically by census bureau, family, and street address. Controls were then matched to cases by year of birth (within the same five year age group). Altogether 107 cases were confirmed by an independent panel of pathologists, clinicians, and cytologists according to diagnostic criteria for pulmonary carcinoma. Each case had one matched 
control (total $=107)$. Data concerning smoking, occupation, residence, diet, prior medical conditions, family history, and other information were collected by questionnaire during a personal interview that took 30-40 minutes to complete. Respondents were mostly the cases and controls themselves $(90 \%$ and $94 \%$ respectively) though for a few subjects the respondent was a close relative. The most common reason for interviewing surrogates instead of cases was due to poor health of the cases whereas the most common reason for controls was their absence from home at the time of interview. All completed questionnaires and medical abstracts were edited by a field supervisor or assistant for completeness and accuracy. Data were coded in Gejiu City by trained coders according to an established coding system and keypunched from coding sheets in Bethesda, MD.

\section{ARSENIC EXPOSURE}

A detailed occupational history included information on job title, worksite, and starting/stopping dates by year for each job held at the YTC for at least one year.

Exposure to arsenic containing ore dust (arsenic exposure) was quantitatively estimated from industrial hygiene data obtained separately for each of the four mines (Laochong, Makuang, Songkuang, Kafang) over five eras (before 1952, 1952-9, 1960-9, 1970-9, and after 1980) and three smelters in three periods (1959-80, 1967-70, and 1969-75).

Airborne dust concentrations at the YTC were first measured in the 1950s, when dry drilling was common and large scale mining was taking place. Underground airborne dust concentrations reached $20-102.6 \mathrm{mg} / \mathrm{m}^{3}$, then fell appreciably to about $6.2 \mathrm{mg} / \mathrm{m}^{3}$ around 1964 when the practice of wet drilling became widespread. ${ }^{3}$ Typically, arsenic represents about $1.34 \%$ of the mined ore by weight as trivalent arsenic $\left(\mathrm{As}_{2} \mathrm{O}_{3}\right)$.

Airborne arsenic concentration before 1970 was estimated as the product of arsenic content of dust times the concentration of dust in the air. Airborne time weighted average arsenic concentration was calculated for ambient air in the mining environment for each mine and smelter based on the arsenic content of dust, the concentration of dust in the air, and the specific time. ${ }^{4}$ After 1970 , direct air arsenic concentrations were measured. Calculated or measured mean values by era are:

$\begin{array}{ll}\text { Era } & \text { Arsenic }\left(\mathrm{mg} / \mathrm{m}^{3}\right) \\ \leq 1951 & 0.42 \\ 1952-9 & 0.06 \\ 1960-9 & 0.04 \\ 1970-9 & 0.03 \\ \geq 1980 & 0.01\end{array}$

Individual worker exposure to arsenic for each job was estimated by using an index (index of arsenic exposure month or IAEM) as follows:
IAEM $=$ time weighted average arsenic concentration $\left(\mathrm{mg} / \mathrm{m}^{3}\right) \times$ exposure month

One IAEM is equivalent to exposure for 25 days (on month) at $1 \mathrm{mg} / \mathrm{m}^{3}$. If total inspired air per day is: estimated at $3.6 \mathrm{~m}^{3}$ and $100 \%$ absorption is assumed then one IAEM is equivalent to $90 \mathrm{mg}$ total arsenie exposure. Cumulative arsenic exposure was estimatedo by summing the exposure levels from each job before diagnosis for cases or to the matched case for controls $\underset{\mathbb{Q}}{\mathbb{Q}}$

OTHER COVARIATES

ڤ

Exposure to radon and radon daughters was als $\vec{\odot}$ estimated from industrial hygiene values measured or $\vec{\omega}$ estimated for each individual mine (Laochange Makuang, Songkuang, Kafang) and era (before 1953. 1953-72, after 1973). Mine, job, and era specifiç exposure to radon daughters was estimated as work ing level months (WLM) for each job for each subject $\vec{\sim}$ A cumulative exposure estimate for each subject was obtained by summing across the estimated WLM fop each job held at the YTC before the diagnosis for case卫 or to the matched case for controls.

Tobacco use in water pipes and cigarettes was ascertained by interview. Because cigarette use wa\$ limited both in duration and amount in these data and thus occurred at levels too low to influence the risk of lung cancer significantly, assessment of tobacco exposure was limited to water pipe use. An index $0 \overrightarrow{6}$ lifetime consumption and pipe years was calculated for water pipe use which incorporated level of use amb duration. Pipe years were determined as average liạng $(50 \mathrm{~g})$ smoked per month times the number of years of reported water pipe use. To avoid ambiguity among subjects who quit smoking after diagnosis of cancer duration of smoking was based on status one yea before diagnosis (for cases) or one year before diagnosis of the matched case (for controls).

\section{OTHER EXPOSURES}

The ore mined in the YTC mines is a complex mixtureD of minerals with the exact mineral content varying by mine, area within the mine, and distance from the surface. The predominant component of the ore is iron oxides $(\sim 37 \%)$, but several minerals suspected of being pulmonary carcinogens are also present in the ore and have been measured in the air in the mines. Ais measurements, for example, from 1977 showed median air values for cadmium of $<0.05 \mu \mathrm{g} / \mathrm{m}^{3}$, nicke?.

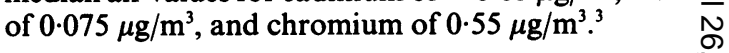

\section{STATISTICAL METHODS}

Statistical analyses were performed using thew statistical analysis software (SAS). ${ }^{5}$ Chi-squared values were calculated using the Mantel-Haentzele procedure. Means of differences were computed 
parametrically using paired $t$ tests and repeated with the Wilcoxon signed rank test, a non-parametric test. PROC LOGIST was used to estimate the exposure odds ratio (OR) as a surrogate for the relative risk (RR) in bivariate and multivariate analyses. All analyses were run with age (the matching factor) as a main effect term. Confidence intervals (CI) of the regression coefficients were estimated under the assumption of normal distribution of the estimates of the coefficients.

\section{Results}

Data were available for 107 living cases of lung cancer from the YTC at the end of 1985. Average age at diagnosis for cases was 57 . Sixty four per cent of cases and $47 \%$ of controls reported no formal education. Forty five $(42 \%)$ of the cases were diagnosed in 1984 , 29 in 1981-3, and the remaining 33 in 1967-80. All but one of the cases had a positive radiograph, $67 \%$ had positive sputum cytology, and $53 \%$ had positive biopsy specimens of which $82 \%$ were squamous cell carcinoma.

The median level of arsenic exposure for cases was 45.9 IAEM (range 0-255.6) whereas the median for controls was only 7.9 IAEM (range 0-132.9) (Wilcoxon signed rank statistic, $S=1655$, $\mathrm{p}=0.0001)$.

Table 1 shows the bivariate (age adjusted) and multivariate estimates of relative risk by quarter of arsenic distribution. Mean values within quarters 1-4 of the distribution of arsenic exposure are $0,11 \cdot 5,46 \cdot 6$, and 97.5 IAEM, respectively. Compared with no arsenic exposure, subjects in the highest quarter of arsenic exposure have a relative risk of $21 \cdot 1$ in the bivariate analysis, a result that is essentially unchanged in the multivariate analysis $(O R=22 \cdot 6)$, despite radon and arsenic exposures being highly

Table 1 Age adjusted relative risk of lung cancer among tin miners from exposure to arsenic

\begin{tabular}{|c|c|c|c|c|}
\hline & \multicolumn{4}{|c|}{ Quarter of arsenic exposure: IAEM (range)* } \\
\hline & $\underset{(0)}{Q u a r t e r} I^{\dagger}$ & $\begin{array}{l}\text { Quarter } 2 \\
(0 \cdot 003-24 \cdot 3)\end{array}$ & $\begin{array}{l}\text { Quarter } 3 \\
(24 \cdot 4-66 \cdot 5)\end{array}$ & $\begin{array}{l}\text { Quarter } 4 \\
(66.6-255.6)\end{array}$ \\
\hline $\begin{array}{l}\text { No of cases } \\
\text { No of }\end{array}$ & 4 & 24 & 41 & 38 \\
\hline $\begin{array}{l}\text { controls } \\
\text { ORf } \\
\text { (95\% CI) } \\
\text { Multivariate }\end{array}$ & $\begin{array}{l}39 \\
1.0 \\
(-)\end{array}$ & $\begin{array}{l}34 \\
6 \cdot 5 \\
(2 \cdot 0-21 \cdot 0)\end{array}$ & $\begin{array}{l}16 \\
24 \cdot 6 \\
(7 \cdot 5-80 \cdot 0)\end{array}$ & $\begin{array}{l}16 \\
21 \cdot 1 \S \\
(6 \cdot 5-68 \cdot 3)\end{array}$ \\
\hline $\begin{array}{l}\text { OR\| } \\
(95 \% \mathrm{CI})\end{array}$ & $\begin{array}{l}1 \cdot 0 \\
(-)\end{array}$ & $\begin{array}{l}6.8 \\
(2 \cdot 0-23.9)\end{array}$ & $\begin{array}{l}23 \cdot 9 \\
(5 \cdot 5-104 \cdot 0)\end{array}$ & $\begin{array}{l}22 \cdot 69 \mid \\
(4 \cdot 8-106 \cdot 4)\end{array}$ \\
\hline
\end{tabular}

*IAEM = Index of arsenic exposure month.

†Reference category.

tControlling for age.

Chi-squared for trend $=35.55, \mathrm{p}<0.0001$.

Multivariate model includes age, radon, year first worked at YTC and pipe years (in addition to arsenic).

१ी Chi-squared for trend $=13.83, p=0.0002$.
Table 2 Comparison of risk of lung cancer by categories of duration and rate of arsenic exposure

\begin{tabular}{|c|c|c|c|}
\hline & \multicolumn{3}{|c|}{ Duration of arsenic exposure (y) } \\
\hline & $(0)^{*}$ & $(1-23)$ & $(24-55)$ \\
\hline \multirow{4}{*}{$\begin{array}{l}\text { No of cases } \\
\text { No of controls } \\
\text { Multivariate } \\
\text { OR } \ddagger \ddagger \\
(95 \% \text { CI })\end{array}$} & $\begin{array}{r}4 \\
39\end{array}$ & $\begin{array}{l}41 \\
48\end{array}$ & $\begin{array}{l}62 \\
20\end{array}$ \\
\hline & $\stackrel{1.0}{(-)}$ & $\begin{array}{l}6 \cdot 8 \\
(2 \cdot 0-23 \cdot 7)\end{array}$ & $\begin{array}{l}19 \cdot 8 \\
(4 \cdot 4-88 \cdot 6)\end{array}$ \\
\hline & \multicolumn{3}{|c|}{ Rate of arsenic exposure (IAEM/y) } \\
\hline & $(0)^{*}$ & $(0.001-2.07)$ & $(2 \cdot 08-6.69)$ \\
\hline $\begin{array}{l}\text { No of cases } \\
\text { No of controls }\end{array}$ & $\begin{array}{r}4 \\
39\end{array}$ & $\begin{array}{l}55 \\
30\end{array}$ & $\begin{array}{l}48 \\
38\end{array}$ \\
\hline $\begin{array}{l}\text { MR+§ } \\
(95 \% \mathrm{CI})\end{array}$ & $\stackrel{1.0}{(-)}$ & $\begin{array}{l}8 \cdot 7 \\
(2 \cdot 5-30 \cdot 5)\end{array}$ & $\begin{array}{l}3.9 \\
(1.0-15 \cdot 3)\end{array}$ \\
\hline
\end{tabular}

* Reference category

† Multivariate model includes age, radon, year first worked at YTC pipe years, and total arsenic exposure (IAEM).

tChi-squared for trend $=15 \cdot 25, \mathrm{p}=0.0001$; model chi-squared = $59.84, \mathrm{p}<0.0001$.

$\S$ Chi-squared for trend $=0.61, p=0.435$; model chi-squared $=57.98$, p $<0.0001$.

correlated in these data (Spearman $r=0.70$, $p=0.0001$ ). Both bivariate and multivariate analyses suggest a monotonic increase in risk with exposure.

Some arsenic exposure was reported in 103 cases and 68 controls. Among arsenic exposed individuals, cases had a median duration of exposure of 28 years (range 2-55), whereas the median for controls was only 15 years (range $1-48$ ). The estimated rate of exposure was 1.99 IAEM/year for cases and 2.39 IAEM/year for controls. Table 2 shows a comparison of risk estimates separately by duration and rate of arsenic exposure.

Table 3 shows cross categorisation of arsenic exposure with tobacco use as pipe months controlling for age and radon exposure. The relative risk for subjects in the highest third of arsenic exposure and the lowest third of tobacco exposure was $5 \cdot 0$, whereas for the highest tobacco and lowest arsenic exposure categories it was only 1.4 .

Table 4 shows cross categorisation of arsenic exposure with radon exposure (controlling for age and pipe months). Relative risk for subjects in the highest third of arsenic exposure and lowest third of radon exposure was 5.4. For the highest radon and lowest arsenic exposure the relative risk was $2 \cdot 2$.

Of the 214 combined cases and controls, 40 had no occupational exposure to arsenic, 142 had exposure to arsenic limited to mining, six had exposure only from smelting, and 26 had exposure to both mining and smelting. Table 5 shows risk estimates for any exposure to arsenic in these jobs compared with no occupational exposure. Highest risk was observed for workers with exposure to both mining and smelting. 
Table 3 Relative risk for lung cancer by cross categories of arsenic and tobacco exposure*

\begin{tabular}{|c|c|c|c|c|c|c|}
\hline & & & \multicolumn{4}{|c|}{ Arsenic category (range) $\dagger$} \\
\hline & & & $\begin{array}{l}\text { Low third } \\
(0-10 \cdot 4)\end{array}$ & $\begin{array}{l}\text { Mid third } \\
(10 \cdot 5-58.5)\end{array}$ & $\begin{array}{l}\text { High third } \\
(58.6-255.6)\end{array}$ & Total \\
\hline $\begin{array}{l}\text { Tobacco } \\
\text { pipe years } \\
\text { (range) } \ddagger\end{array}$ & $\begin{array}{l}\text { Low third } \\
(0-84)\end{array}$ & $\begin{array}{l}\text { No of cases } \\
\text { No of controls } \\
\text { OR } \\
(95 \% \text { CI }) \\
\text { No of cases } \\
\text { No of controls } \\
\text { OR } \\
(95 \% \text { CI }) \\
\text { No of cases } \\
\text { No of controls } \\
\text { OR } \\
(95 \% \text { CI }) \\
\text { No of cases } \\
\text { No of controls } \\
\text { OR } \\
(95 \% \text { CI })\end{array}$ & $\begin{array}{l}8 \\
31 \\
1.08 \\
\left(\frac{-}{4}\right) \\
4 \\
16 \\
1 \cdot 0 \\
(0 \cdot 3-3 \cdot 8) \\
3 \\
9 \\
1 \cdot 4 \\
(0 \cdot 3-6 \cdot 5) \\
15 \\
56 \\
1 \cdot 0 \\
(-)\end{array}$ & $\begin{array}{l}10 \\
10 \\
3 \cdot 2 \\
(1 \cdot 0-10 \cdot 9) \\
16 \\
8 \\
4 \cdot 9 \\
(1 \cdot 4-16 \cdot 7) \\
20 \\
7 \\
8 \cdot 9 \\
(2 \cdot 7-29 \cdot 8) \\
46 \\
25 \\
4 \cdot 6 \\
(2 \cdot 0-10 \cdot 4)\end{array}$ & $\begin{array}{l}8 \\
4 \\
5 \cdot 0 \\
(1 \cdot 1-22 \cdot 4) \\
17 \\
11 \\
4 \cdot 4 \\
(1 \cdot 4-14 \cdot 3) \\
20 \\
11 \\
4 \cdot 9 \\
(1 \cdot 4-16 \cdot 7) \\
45 \\
26 \\
4 \cdot 0 \\
(1 \cdot 6-9 \cdot 6)\end{array}$ & $\begin{array}{l}26 \\
45 \\
1 \cdot 0 \\
\left(-\frac{)}{37}\right. \\
35 \\
1 \cdot 2 \\
(0 \cdot 6-2 \cdot 5) \\
43 \\
27 \\
1 \cdot 6 \\
(0 \cdot 7-3 \cdot 6)\end{array}$ \\
\hline
\end{tabular}

*Controlling for age and pipe months.

tIndex of arsenic exposure month (IAEM).

\# Average liang per month times number of years smoked.

§Reference category.

\section{Discussion}

In this study of the relation of exposure to arsenic from mining and smelting to lung cancer among tin miners in southern China arsenic is observed to be a strong risk factor for lung cancer, with the highest quartile of exposure having in excess of a 20 -fold rise in risk compared with non-arsenic exposed subjects after controlling for tobacco and radon exposures. Further, a strong dose response relation is observed.

Our observations on duration and intensity of arsenic exposure, similar to our findings for radon (Y-L Qiao, unpublished data) suggest that duration of arsenic exposure is more important as a risk factor for lung cancer than intensity. This observation may have $\square$ important implications for environmental exposures to arsenic outside the occupational setting.

Most previous studies of the effect of smoking and arsenic exposure to lung cancer have not observed an $\stackrel{\mathbb{}}{-}$ interaction ${ }^{6-9}$; however, at least one recent study did $\overrightarrow{0}$ see such an effect. ${ }^{10}$ We find little evidence that tobaccoso exposure affects risk estimates for arsenic exposure. As shown in table 3 , risks in the highest tertile of arsenic exposure are similar for all categories of tobacco use.

Evaluating the potential interaction between arsenic $\stackrel{2}{\circ}$

Table 4 Relative risk for lung cancer by cross categories of arsenic and radon exposure*

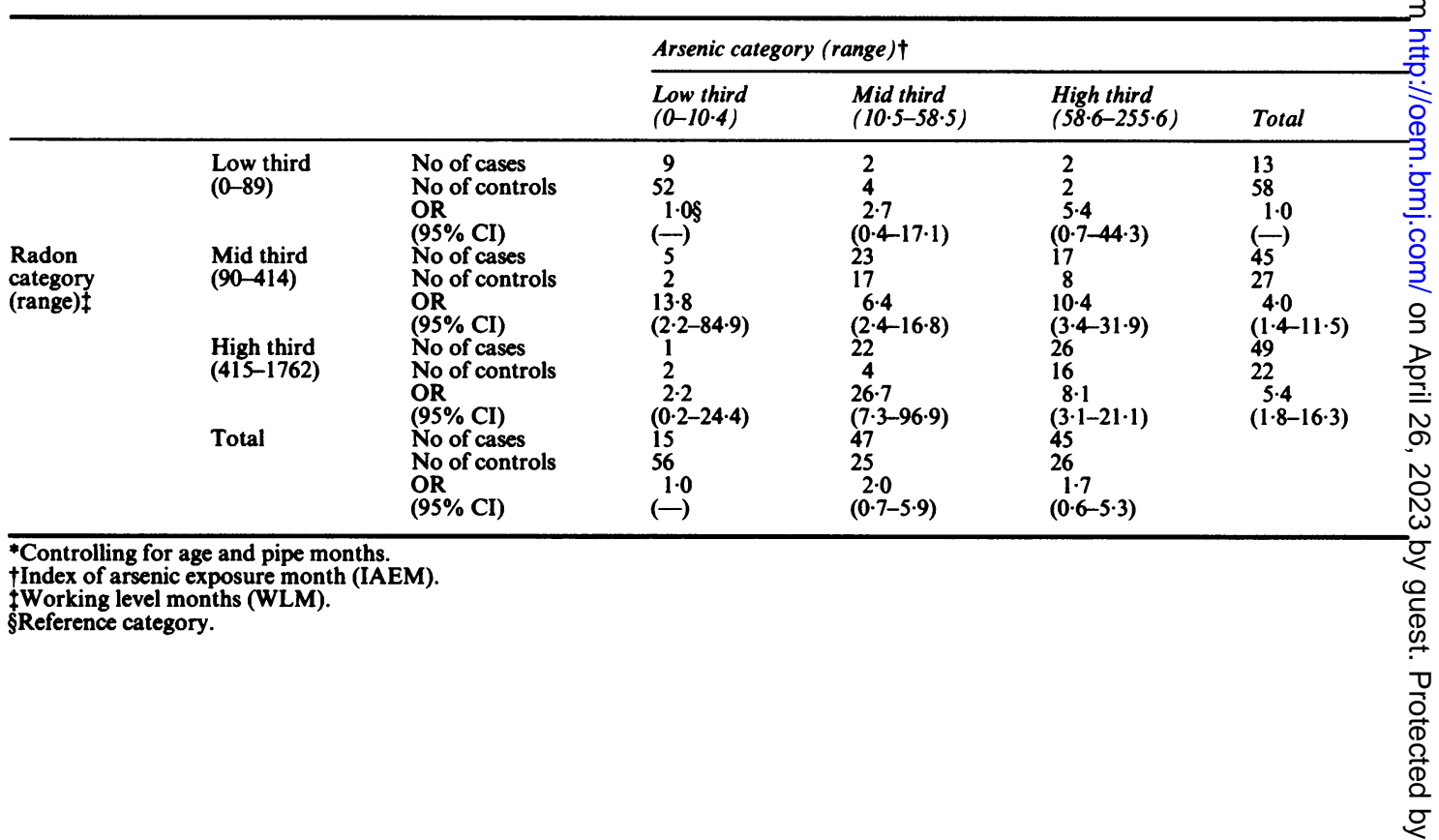


Table 5 Risk of lung cancer by type of arsenic exposure*

\begin{tabular}{lccrl}
\hline $\begin{array}{l}\text { Arsenic } \\
\text { exposure }\end{array}$ & $\begin{array}{l}\text { No of } \\
\text { cases }\end{array}$ & $\begin{array}{l}\text { No of } \\
\text { controls }\end{array}$ & OR $\dagger$ & $95 \%$ CI \\
\hline $\begin{array}{l}\text { None } \\
\begin{array}{l}\text { Smelter only } \\
\text { Mining only }\end{array}\end{array}$ & 3 & 37 & $1 \cdot 0$ & $-\overline{1 \cdot 7-91.9}$ \\
$\begin{array}{l}\text { Smelter }+ \\
\text { mining }\end{array}$ & 19 & 60 & $12 \cdot 3$ & $2 \cdot 4-32 \cdot 2$ \\
\hline
\end{tabular}

*Controlling for age, radon, and pipe years.

†Odds ratio.

and radon is complex. The relative increase in risk for increasing arsenic exposure in the lowest category of radon exposure is high $(1 \cdot 0,2 \cdot 7$, and $5 \cdot 4$, respectively), whereas risk estimates in the mid and high third radon categories are highly variable. For radon vis-a-vis arsenic, relative increases in risk from radon are high in the mid third arsenic category $(2 \cdot 7,6 \cdot 4$, and $26 \cdot 7$, respectively) but are quite variable elsewhere. The high correlation between arsenic and radon exposure makes assessing exposure to each agent individually problematical. Perhaps the clearest view of the risk of arsenic independent of radon is found by examining the lowest radon exposure category from table 4 where the contrast between high and low categories of arsenic exposure is a relative risk of 5.4 . This estimate is consistent with the up to 10 -fold rise in risk reported in other studies of arsenic exposure as reviewed by Axelson. " Even this category of low radon exposure (up to 89 WLM), however, may not be free of influence from radon. Archer's recent review of a large number of studies of underground miners in relation to radon observed a significant excess of lung cancer in groups with cumulative radon exposure as low as 25 WLM. ${ }^{12}$ Whereas most subjects in this study had exposure to arsenic only from mining, a few had exposure only from smelting or from both mining and smelting. Our attempts to assess magnitude of risk from different sources of arsenic exposures suggest that the relative risk for mining only is slightly less than for smelting only which is, in turn, less than for mining plus smelting together. Although numerous studies have documented increased risk for lung cancer from arsenic exposure to smelting, ${ }^{6-913-21}$ few studies have directly considered the issue of the risk of lung cancer from underground exposure to arsenic, and results from the studies that have done so have been conflicting. ${ }^{9223}$ Although an influence from radon or other mine exposures cannot be completely excluded, data from the current study suggest that exposure to arsenic from mining, independent of exposure to smelting, results in an increased risk of lung cancer.

In conclusion, we studied the relation of exposure to arsenic to lung cancer among workers at the tin mines in Yunnan, China, and observed an increased risk among workers exposed to arsenic. Although this study was based on prevalent cases of lung cancer so that we measured characteristics of both incidence and survivorship, the comparisons are valid because we have used a comparable series of controls. The risk of lung cancer increased directly with exposure to arsenic, appeared to be independent of exposure to tobacco, was more related to duration than intensity of exposure, and was comparable for exposure to mining and smelting.

We gratefully acknowledge the help of Drs Li Guo and Fu-Min Zhang of the Labor Protection Institute of the Yunnan Tin Corporation (People's Republic of China), and the help of Carol Giffen of Information Mangements Services, Inc (Silver Spring, Maryland, USA).

This study was supported in part by the China State Science and Technology Commission and the US National Cancer Institute (NO1-CP4-1019-00).

Requests for reprints from China to You-Lin Qiao, Department of Epidemiology, Cancer Institute, CAMS, Beijing 100021, China, and from other countries to Philip $\mathbf{R}$ Taylor, NCI/NIH, EPN, Rm 211, Bethesda, MD.

\section{References}

1 International Agency for Research on Cancer. Monographs on the evaluation of the carcinogenic risk of chemicals to humans, Vol 23. Some metals and metallic compounds. Lyon: IARC, 1980: 101-14.

2 Yao S-X, Zhang F-M. Research on the epidemiology of lung cancer among miners at YTC. Cancer Research on Prevention and Treatment 1984;11:105-10. (In Chinese.)

3 Liu Y-T, Chen Z, Wang A. Approach on etiology of Yunnan tin miner's lung cancer. Chinese Journal of Industrial Hygiene and Occupational Disease 1987;5:20-1. (In Chinese.)

4 Mao B-L. An etiologic approach to lung cancer in Yunnan tin miners. Tumor 1981;2:1-5. (In Chinese.)

5 SAS Institute, Inc. SAS user's guide. In: Cary, NC: SAS Institute, 1982.

6 Pinto SS, Enterline PE, Henderson V, Varner MD. Mortality experience in relation to a measured arsenic trioxide exposure. Environ Health Perspect 1977;19:127-30.

7 Pinto SS, Henderson V, Enterline PE. Mortality experience of arsenic-exposed workers. Arch Environ Health 1978;33:325-30.

8 Rencher AC, Carter MW, McKee DW. A retrospective epidemiological study of mortality at a large Western copper smelter. J Occup Med 1977;19:754-8.

9 Axelson O, Dahlgren E, Jansson CD, Rehnlund SO. Arsenic exposure and mortality: a case-referent study from a Swedish copper smelter. Br J Ind Med 1978;35:8-15.

10 Pershagen G, Wall S, Taube A, Linnman L. On the interaction between occupational arsenic exposure and smoking and its relationship to lung cancer. Scand $J$ Work Environ Health 1981;7:302-9.

11 Axelson O. Arsenic compounds and cancer. In: Vainio V, ed. Occupational cancer and carcinogenesis. Washington: Hemisphere Publishing Corp, 1980:1229-35.

12 Archer VE. Lung cancer risks of underground miners: cohort and 
case-control studies. Yale J Biol Med 1988;61:183-93.

13 Lee AM, Fraumeni JF, Jr. Arsenic and respiratory cancer in man: an occupational study. J Natl Cancer Inst 1969;42:1045-52.

14 Milham S, Jr, Strong T. Human arsenic exposure in relation to a copper smelter. Environ Res 1974;7:176-82.

15 Tokudome S, Kuratsune M. A cohort study on mortality from cancer and other causes among workers at a metal refinery. Int $J$ Cancer 1976;17:310-7.

16 Enterline PE, Marsh GM. Mortality studies of smelter workers. Am J Ind Med 1980;1:251-9.

17 Lubin JH, Pottern LM, Blot WJ, Tokudome S, Stone BJ, Fraumeni JF, Jr. Respiratory cancer among copper smelter workers: recent mortality statistics. J Occup Med 1981;23: $779-84$.

18 Higgins I, Welsh K, Oh M, Bond G, Hurwitz P. Influence of arsenic exposure and smoking on lung cancer among smelter $\overline{\overline{2}}$ workers: a pilot study. Am J Ind Med 1981;2:33-41.

19 Enterline PE, Marsh GM. Cancer among workers exposed to $\checkmark$ arsenic and other substances in a copper smelter. $A m$ Epidemiol 1982;116:898-911.

20 Lee-Feldstein A. Cumulative exposure to arsenic and its relationship to respiratory cancer among copper smelter employees. $f$ Occup Med 1986;28:296-302.

21 Enterline PE, Henderson VL, Marsh GM. Exposure to arsenic and음 respiratory cancer: a reanalysis. Am J Epidemiol 1987;125: 929-38.

22 Osburn HS. Cancer of the lung in Gwanda. Cent Afr J Med 1957;3:215-23.

23 Osburn HS. Lung cancer in a mining district in Rhodesia. $S$ Afr Med J 1969;43:1307-12. 